\title{
Efficacy and Safety of Sunflower Oil for Mild to Moderate Plaque-type Psoriasis: A Double-blind, Randomized Controlled Trial
} $\$$

\author{
Franchesca Marie D. Ilagan, MD; Eleanor L. Letran, MD; \\ Bernardita O. Policarpio, MD
}

\section{ABSTRACT}

Background: Psoriasis is a chronic, complex, inflammatory disease that needs safe and effective treatment options to decrease its disease burden.

Objectives: To determine the efficacy and safety of sunflower oil in mild to moderate plaque-type psoriasis at the outpatient department of a tertiary hospital.

Methods: This was an 8-week, single-center, randomized, double-blind controlled trial that compared the efficacy and safety of sunflower oil + placebo cream (Group SO), betamethasone valerate cream + placebo oil (Group BC), sunflower oil + betamethasone valerate cream (Group SO$\mathrm{BC}$ ) in mild to moderate plaque-type psoriasis. Psoriasis Area Severity Index (PASI) was used to measure the extent of psoriasis by assessing the erythema, induration, scaling, and body surface area involvement. The difference from baseline PASI was recorded. The Dermatology Life Quality Index (DLQI) questionnaire was used to measure the impact of psoriasis on the patient's quality of life.

Franchesca Marie D. Ilagan, MD

ica_ilagan@yahoo.com

Department of Dermatology,

University of Santo Tomas Hospital, Espana,

Manila, Philippines
Results: Fifty-one patients were randomized and blinded to three treatment arms; evaluated at baseline, week 4 and 8 . The proportion of patients who achieved PASI $\geq 50$ at week 4 was $29 \%$ in Group SO, 38\% in Group BC, and 60\% in Group SO-BC. By week 8, Groups SO and BC achieved $80 \%$ while Group SO-BC achieved 93\%. There was significant decline of PASI at week 4 and week 8 compared to baseline. The mean percentage change of PASI was highest at Group SO-BC followed by Group BC and lastly Group SO at week 4 and week 8 . The mean reduction in score for scaling was significantly higher in Group SO-BC. Mean reduction in induration and erythema was not statistically significant across the three groups. There was $40-50 \%$ improvement in DLQI scores in all groups. There were no adverse events.

Conclusion: This study showed that sunflower oil is effective and safe in mild to moderate plaque-type psoriasis.

Key words: sunflower oil, randomized controlled trial, psoriasis

\section{INTRODUCTION}

Psoriasis, a chronic, complex, inflammatory disease affecting the skin and nails, is considered a global problem with prevalence ranging from 
$0.09 \%-11.4 \%$. Approximately $2-5 \%$ of the world's population [1,2] with 1-2 million Filipinos are suffering from psoriasis.[3] It has a complex pathophysiology involving $T$ cells, dendritic cells, cytokines, genetics, and keratinocyte differentiation.

Currently, there is no cure for psoriasis. The goals of treatment include control of lesions, symptoms and improvement in the quality of life.[1] Eighty percent of patients with psoriasis have mild-moderate disease [4] for which topical therapy is the modality of choice for less than $10 \%$ of the body surface area. The topical corticosteroid is most commonly used due to its potent anti-inflammatory properties. However, long-term use may result in undesirable side effects of telangiectasia, atrophy, purpura, folliculitis, and striae [5] causing physicians and patients to have steroid phobia leading to treatment non-adherence. $[6,7]$ There is need for a long-term safe and effective treatment for patients with psoriasis to decrease its disease burden.

Sunflower oil has been shown to have moisturizing and anti-inflammatory properties.[8-11] Its high linoleic content causes reduction of TNF-alpha which plays a major part in the pathogenesis of psoriasis. It has also been shown to have no adverse skin reactions. $[10,12]$

The objective of this study was to determine the efficacy and safety of sunflower oil in mild to moderate plaque-type psoriasis in comparison to betamethasone valerate cream at the outpatient department of a tertiary hospital. It specifically aimed to compare the effect of sunflower oil + placebo cream (Group SO) versus betamethasone valerate cream + placebo oil (Group BC) versus sunflower oil + betamethasone valerate cream (Group SO$\mathrm{BC})$ at weeks 4 and 8 in terms of: 1) the proportion of patients achieving Psoriasis Area and Severity Index (PASI) $\geq 50 ; 2$ ) mean PASI scores; 3) mean percentage improvement of PASI; 4) mean reduction in score of erythema, scaling, and induration; 5) mean reduction in Dermatology Life Quality Index (DLQI) score at $8^{\text {th }}$ week of treatment compared to baseline and; 6) incidence of adverse events for each treatment group at the $4^{\text {th }}$ and $8^{\text {th }}$ week.

\section{METHODOLOGY}

\section{Research Design}

This study was an 8-week, single-center, randomized, double-blind controlled trial that compared the efficacy and safety of sunflower oil + placebo cream (Group SO), betamethasone valerate cream + placebo oil (Group BC), sunflower oil + betamethasone valerate cream (Group SO-BC) in patients with mild to moderate plaque-type psoriasis.

This study was approved by the hospital's Institutional Review Board and was conducted in accordance to the accepted ethical research practices of the International Conference on Harmonisation Good Clinical Practice regulations and guidelines. Informed consent was obtained from all participants prior to entering the study. This study was investigator-initiated and not industry funded or company sponsored and had no potential conflicts of interest.

\section{Participants}

Patients aged 18 years old and above with mild to moderate $1 \leq 10 \%$ of body surface area and PASI of $\leq 15$ ) chronic plaque-type psoriasis who sought treatment at the outpatient department of a tertiary hospital between February 2019 and August 2019. Exclusion criteria included facial, scalp, palms, soles, nail, and intertriginous psoriasis, guttate, inverse, erythrodermic, pustular, and psoriatic arthritis, patients with known hypersensitivity to steroid or sunflower oil, pregnant and breastfeeding women, patients with psychiatric illnesses, and those who refused or were unable to provide consent.

\section{Interventions}

The aim of the study was to determine the efficacy and safety of sunflower oil in mild to moderate psoriasis. In this study, sunflower oil was compared to betamethasone valerate cream as a standard of treatment for mild to moderate plaque type psoriasis. In order to facilitate blinding, a placebo cream which has the same composition of the steroid cream minus its active ingredient was used with sunflower oil in Group SO. The second arm (Group BC), betamethasone valerate cream was given with placebo which was mineral oil. The third arm (Group SO-BC) was made to determine the additive effect of the combination of sunflower oil with betamethasone valerate cream.

The study coordinator was blinded to patient allocation and obtained informed consent from the patients. The washout periods of previous treatments 
were 2 weeks for topical treatments and UVB phototherapy, one month for systemic treatment and three months for biologics.[13-16]

The participants were randomly assigned in a $1: 1: 1$ ratio into the three treatment arms (Group SO, Group BC, and Group SO-BC) by a research assistant. Patients on Group SO applied a placebo cream $2 x$ a day on the affected areas followed by the sunflower oil; Group BC applied betamethasone valerate cream $2 x$ a day on the affected areas followed by the placebo oil, and Group SO-BC applied betamethasone valerate cream $2 x$ a day on the affected areas followed by sunflower oil. In all treatment groups, the cream was applied first followed by the oil after 15 minutes.[17] The treatment was applied daily until resolution of lesions or up to 8 weeks, whichever came first. The research assistant showed the application of the treatment materials and a return demo was done by the participant. All trial products namely the $100 \%$ sunflower seed oil and betamethasone valerate cream utilized were approved by the Food and Drug Administration (FDA) of the Philippines.

Cleansing agents used were similar in all groups.

Baseline assessment was done on Day 0 which included the demographic data lage, sex, comorbidities, previous psoriasis treatment, and disease duration) (Appendix A), Physicians Area and Severity Index (PASI), and Dermatology Life Quality Index (DLQI). Baseline measures and PASI was done by the study investigator while the DLQI on Day 0 and week 8 was self-administered.

Treatment was discontinued anytime if (1) the patient requested to withdraw from the study; (2) there was development of severe adverse reaction; (3) there was exacerbation or worsening of the clinical condition to severe psoriasis or progression to pustular, erythrodermic or psoriatic arthritis.

\section{Outcomes}

The primary outcome of this study was the proportion of patients achieving PASI $\geq 50$ at the $4^{\text {th }}$ and $8^{\text {th }}$ week compared to baseline in the three treatment arms. Studies showed that PASI 50 is a meaningful cut-off value and translates to good clinical improvement and DLQI score. Patients who achieved PASI 75 did not seek treatment until PASI was below 50 from baseline and effective therapies were differentiated from placebo at PASI 50. It was concluded that PASI 50 is considered a clinically significant endpoint in patients with psoriasis.[18-20]

The secondary outcomes were assessment of clinical response in each treatment group at weeks 4 and 8 based on mean PASI scores, mean percentage improvement of PASI, mean reduction in score of erythema, scaling, and induration, mean reduction in DLQI score at $8^{\text {th }}$ week of treatment compared to baseline and incidence of adverse events for each treatment group at the $4^{\text {th }}$ and $8^{\text {th }}$ week.

The PASI and the DLQI are the most widely used tools in clinical trials of psoriasis.[18,21,22] PASI was determined by grading erythema, induration, scaling, and the body surface area involvement. It is a quantitative measure of the extent of psoriasis and a validated measure of treatment response.[21] The changes in the PASI score from baseline determines the efficacy of treatment given (Appendix B). [18] The $D L Q I$ is a simple and easy quantitative measure of the impact of skin disease to the person's quality of life which can be applied to patients with psoriasis (Appendices C-D).[23]

Incidence of adverse events such as pruritus, pain, and increase in erythema were recorded. A physician assessor assessed the outcome measures at the $4^{\text {th }}$ and $8^{\text {th }}$ week of follow-up. Patients were asked to follow-up every 2 weeks to sustain compliance with the medications.

\section{Sample Size}

PASS 2008 was used to calculate the minimum sample size of the study. A previous study showed that PASI 50 was achieved by $88 \%$ of psoriasis patients after treatment with betamethasone valerate.[24] It was assumed that $50 \%$ of Group SO and $100 \%$ of Group SO-BC patients will achieve PASI 50 at the end of the 8-week treatment. Sample size computation for Chi-square test was used specifying an effect size of 0.53 , degree of freedom of 2 , and alpha equal to 0.05 . A sample of 46 patients with mild to moderate psoriasis achieved $90 \%$ power to detect a difference in the proportion of patients who achieved PASI 50 at the end of the treatment period. The sample size was then increased to 51 to account for $10 \%$ potential drop-out (Appendix E). 


\section{Sampling, Randomization, and Blinding}

Prior to start of the study the statistician generated the allocation schedule. A list of patient numbers were randomly assigned in a 1:1:1 ratio into three treatment groups using www.randomization.com. Block randomization technique was employed with random block sizes of 17 . The allocation schedule was given to the research assistant who then prepared sequentially numbered opaque containers for creams and amber colored bottles for oils according to the allocation schedule. The allocation schedule was concealed from other study investigators and patients until the end of the study.

Convenience sampling was employed in the selection of study participants. Each patient was screened by a primary investigator for eligibility during their visit to the outpatient department. Upon completion of the washout period, participants were assigned a number sequentially according to the time they entered the study. Eligible patients were referred to the study coordinator to obtain their written consent and baseline data. Treatment materials based on their study number and instructions to the patients were also given.

A blinded physician assessor assessed the outcome measures which were PASI, DLQI, and adverse events at the $4^{\text {th }}$ and $8^{\text {th }}$ week of follow-up.

\section{Statistical Methods}

Data were encoded in MS Excel by the researcher. Stata MP version 14 was used for data processing and analysis. Continuous variables were presented as mean/standard deviation (SD) and were analyzed using One-Way Analysis of Variance (ANOVA) or Kruskal-Wallis test. Posthoc analyses using Tukey Honestly Significant Difference (HSD) and Dunn's test were performed for significant results. Categorical variables were presented as a frequency/percentage and were analyzed using the Chi-square test or Fisher's exact test.

The proportion of patients who achieved PASI 50 for each treatment group at week 4 and week 8 were compared using Fisher's exact test. In order to minimize alpha error, Bonferonni correction was applied such that alpha is set at 0.025 . Within group differences in PASI score over time was analyzed using Repeated Measures ANOVA.
The mean change in PASI improvement and DLQI scores by treatment group were analyzed using One-Way ANOVA, and significant results were further analyzed using Tukey HSD. Adverse events were compared by the treatment group using the Chi-square test or Fisher's exact test. $P$ values $\leq 0.05$ were considered statistically significant. Intention-to-treat analysis was followed and in order to assess the effect of dropouts or lost to follow-up participants a per-protocol analysis was also performed.

\section{RESULTS}

\section{Study Population}

A total of 51 patients were enrolled into the study, 17 patients in each of the treatment arms. Of the 51 patients, 45 were included in the per protocol analysis since 6 patients were lost to follow up or withdrew from the study. A flow diagram of patients' treatment and reasons for discontinuation are shown in Figure 1.

Baseline demographics and characteristics of patients per treatment arm are shown in Table 1. The median age is 40 years old (IQR: 29-62 years old). There was no significant difference between baseline demographics and characteristics of patients in the three treatment groups in terms of age, comorbidities, BMI, duration of psoriasis, previous treatments for psoriasis, mean PASI and mean DLQI at baseline. The proportion of male patients was significantly higher in Group SO-BC (82\%) compared to Group BC $(41 \%)$ but not to Group SO (59\%). A majority of patients in the study were overweight or obese and had used topical steroids in the past.

\section{Psoriasis Area and Severity Index (PASI) $\geq \mathbf{5 0}$}

Figure 2 shows the proportion of patients who achieved PASI $\geq 50$ by treatment group at week 4 and week 8 . At week 4, PASI 50 was achieved by $29 \%$ patients in Group SO, 38\% in Group BC, and $60 \%$ in Group SO-BC. There was further increase in a proportion of patients who achieved PASI 50 in week 8. Eighty percent of patients in both Groups SO and BC, and $93 \%$ of patients in Group SO-BC achieved PASI 50 at week 8 . The proportion of patients who achieved PASI 50 did not significantly differ across treatment arms in both week 4 (p-value $=0.204)$ and week 8 ( $p$-value $=0.668)$. 


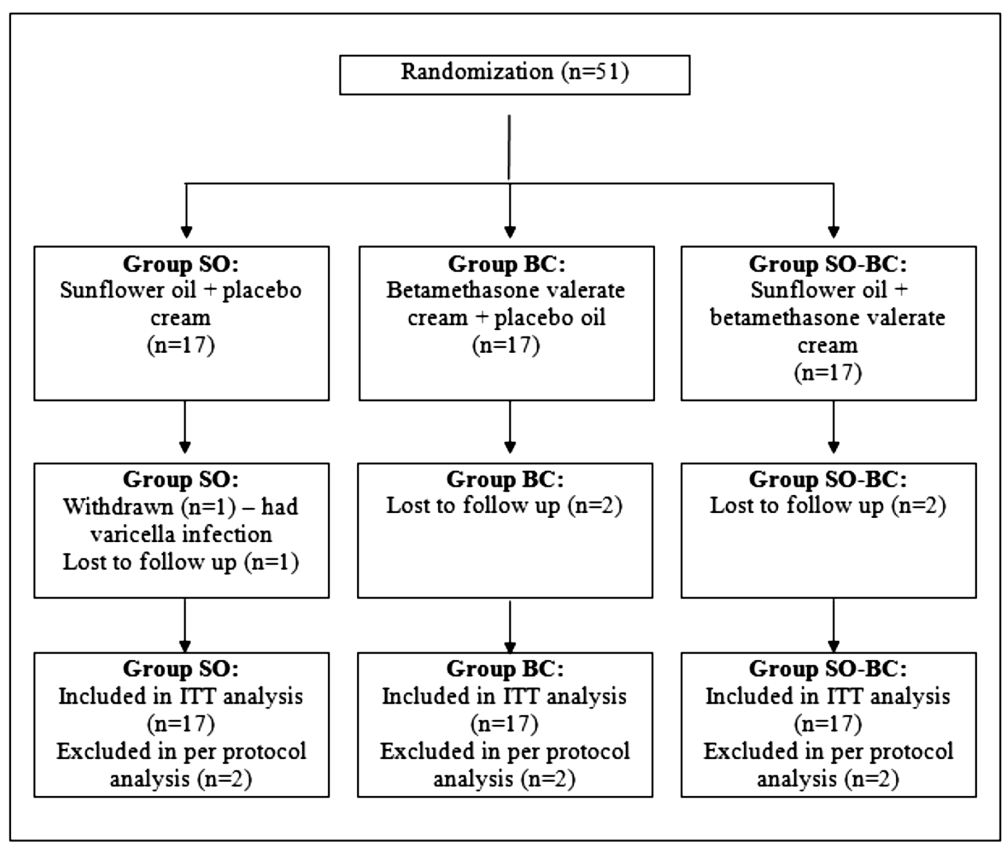

ITT, intention to treat.

Figure 1. Schematic diagram of patient disposition for Groups SO, BC, and SO-BC.

Table 1. Demographics and baseline characteristics of patients with mild to moderate plaque-type psoriasis by treatment arm seen at a tertiary hospital $(n=51)$

\begin{tabular}{|c|c|c|c|c|}
\hline Characteristics & $\begin{array}{c}\text { Group SO: } \\
\text { Sunflower oil + } \\
\text { placebo cream } \\
(n=17) \\
n(\%)\end{array}$ & $\begin{array}{c}\text { Group BC: } \\
\text { Betamethasone } \\
\text { valerate cream + } \\
\text { placebo oil } \\
(n=17) \\
n(\%)\end{array}$ & $\begin{array}{c}\text { Group SO-BC: } \\
\text { Sunflower oil + } \\
\text { betamethasone } \\
\text { valerate cream } \\
(n=17) \\
n(\%)\end{array}$ & P value \\
\hline Age (in years), median & $\begin{array}{c}29 \\
\text { [IQR: } 21-60]\end{array}$ & $\begin{array}{c}51 \\
{[1 Q R: 38-63]}\end{array}$ & $\begin{array}{c}38 \\
{[\text { IQR: } 31-58]}\end{array}$ & 0.2139 \\
\hline \multicolumn{5}{|l|}{ Sex } \\
\hline Male & $10(59)$ & $7(41)$ & $14(82)$ & $0.048^{*}$ \\
\hline Female & $7(42)$ & $10(59)$ & $3(18)$ & \\
\hline \multicolumn{5}{|l|}{ Comorbidities } \\
\hline Hypertension & $3(18)$ & $7(41)$ & $4(24)$ & 0.384 \\
\hline Diabetes mellitus & 0 & $1(6)$ & $4(24)$ & 0.111 \\
\hline Dyslipidemia & $2(12)$ & $2(12)$ & 0 & 0.528 \\
\hline \multicolumn{5}{|l|}{ BMI } \\
\hline Normal & $4(24)$ & 0 & $2(12)$ & 0.145 \\
\hline Overweight/Obese & $13(76)$ & $17(100)$ & $15(88)$ & \\
\hline $\begin{array}{l}\text { Psoriasis duration (in months), } \\
\text { median }\end{array}$ & $\begin{array}{c}72 \\
\text { [IQR: 24-120] }\end{array}$ & $\begin{array}{c}108 \\
\text { [IQR: } 36-180]\end{array}$ & $\begin{array}{l}36 \\
\text { [IQR: 28-120] }\end{array}$ & 0.5854 \\
\hline \multicolumn{5}{|l|}{ Previous treatment for psoriasis } \\
\hline Topical & $17(100)$ & $17(100)$ & $14(82)$ & 0.098 \\
\hline Phototherapy & $2(12)$ & $1(6)$ & $1(6)$ & 1.000 \\
\hline Systemic & $2(12)$ & $4(24)$ & $6(35)$ & 0.330 \\
\hline PASI, mean & $2.18 \pm 0.92$ & $2.76 \pm 0.95$ & $3.09 \pm 1.56$ & 0.0879 \\
\hline DLQI, mean & $6.24 \pm 2.56$ & $5.82 \pm 1.59$ & $6.59 \pm 5.37$ & 0.8221 \\
\hline
\end{tabular}

IQR, interquartile range; PASI, Physicians Area and Severity Index; DLQI, Dermatology Life Quality Index 


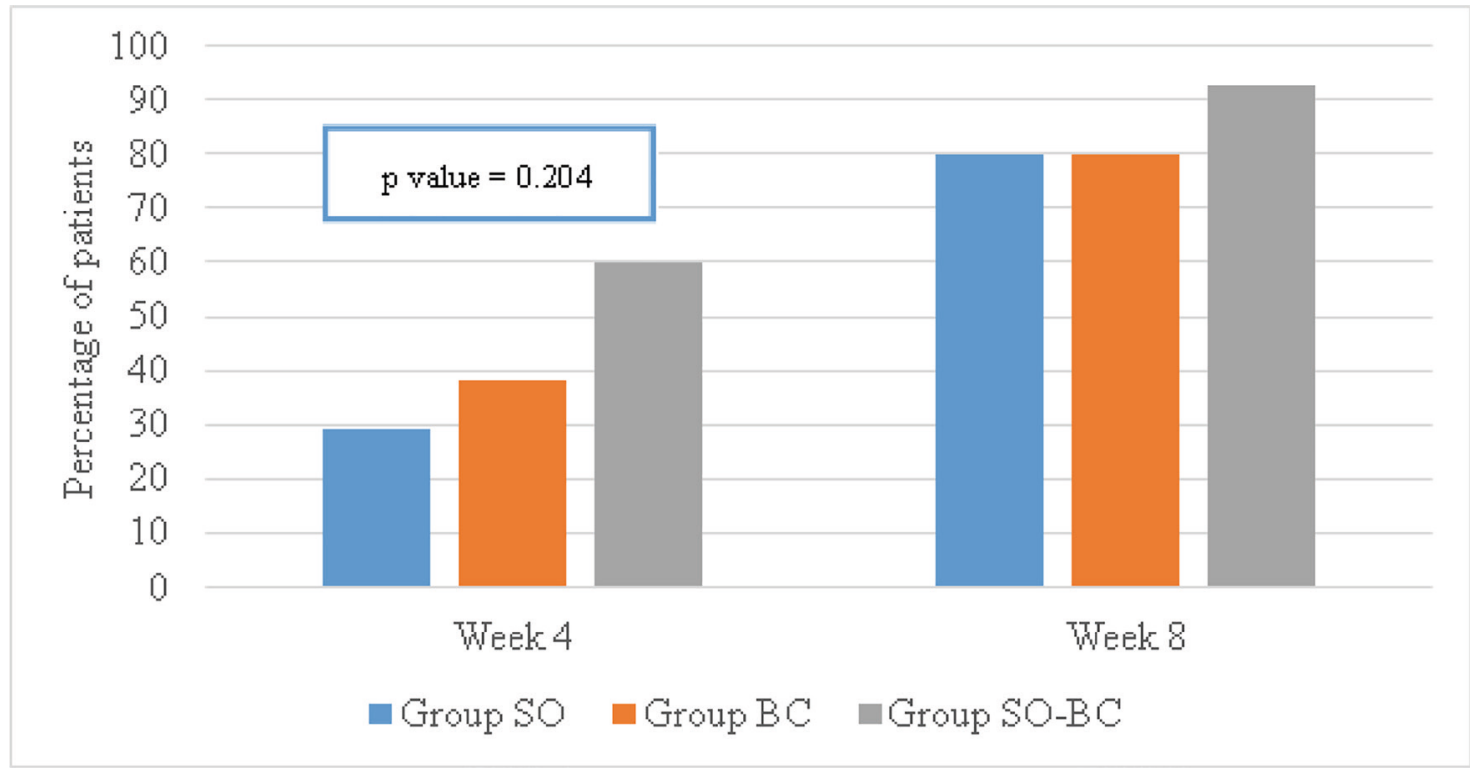

Figure 2. Percentage of patients who achieved PASI 50 at week 4 and week 8 by treatment $\operatorname{arm}(n=51)$

\section{Mean PASI Score}

Figure 3 shows the decreasing trend in mean PASI score at week 4 and week 8 compared to baseline in all treatment groups. Repeated measures ANOVA showed significant decrease in mean PASI score at week 4 and week 8 compared to baseline PASI in all three groups (p-value $<0.00001$ ). Post-hoc analysis using Tukey HSD showed that in all three groups mean baseline PASI was significantly higher compared to mean PASI score at week 4 and week 8 ; and mean PASI score at week 4 was still significantly higher compared to week 8 .

\section{Mean Percentage Improvement of PASI From Baseline}

Figure 4 shows mean percent improvement of PASI from baseline in all treatment groups. At week 4, the mean percent change of PASI was highest at Group SO-BC $(56.12 \% \pm 27.72)$ followed by Group BC $(45.50 \% \pm 24.55)$ and lastly Group SO $136.48 \%$ $\pm 21.17)$. There was a further increase in mean percentage improvement of PASI at week 8 in Group SO-BC (76.25\% \pm 18.59), Group BC $169.79 \% \pm$ $25.83)$, and Group SO (65.03\% \pm 27.24$)$. There was no significant difference in mean percentage

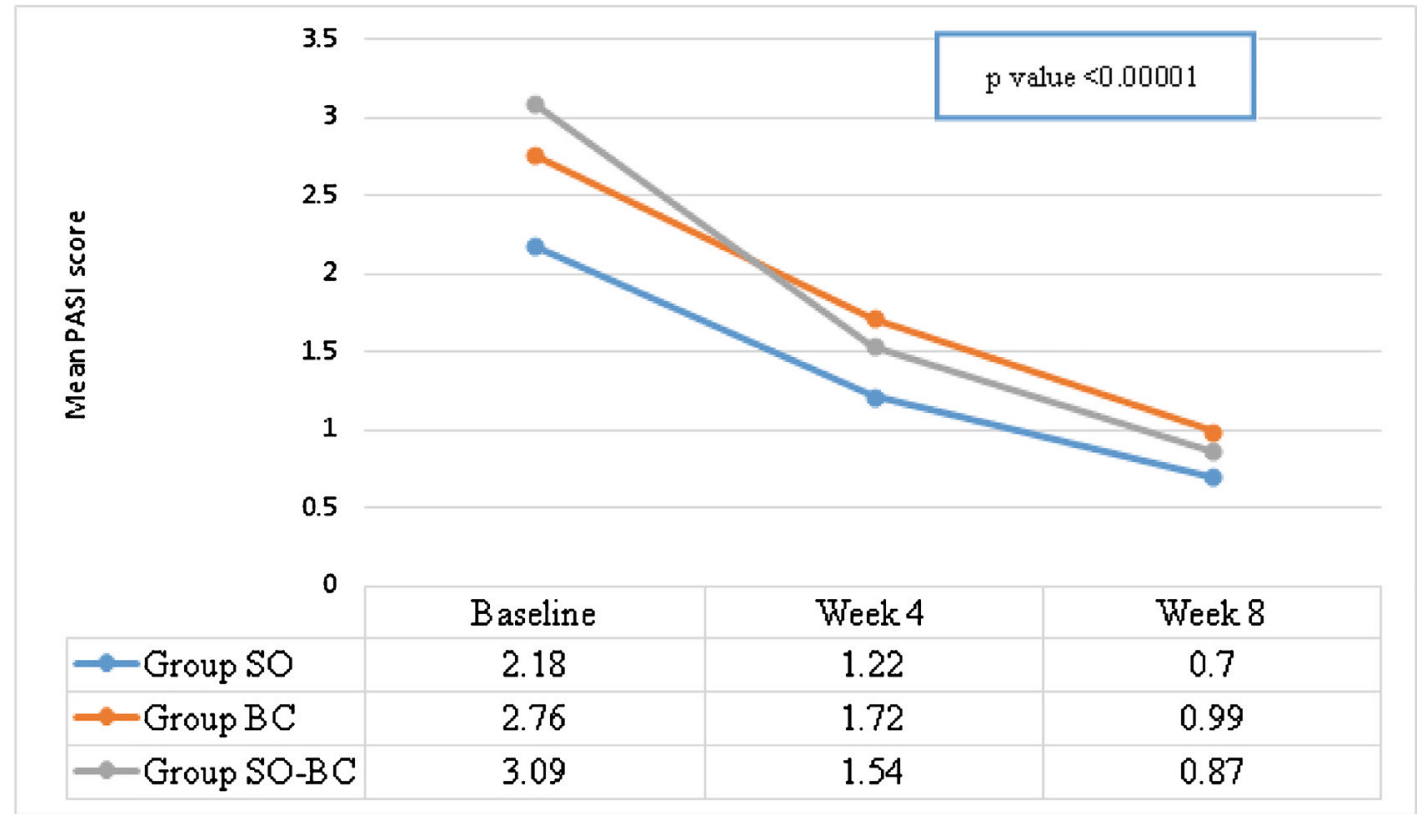

Figure 3. Mean PASI score at baseline, week 4 , and week 8 by treatment arm $(n=51)$ 


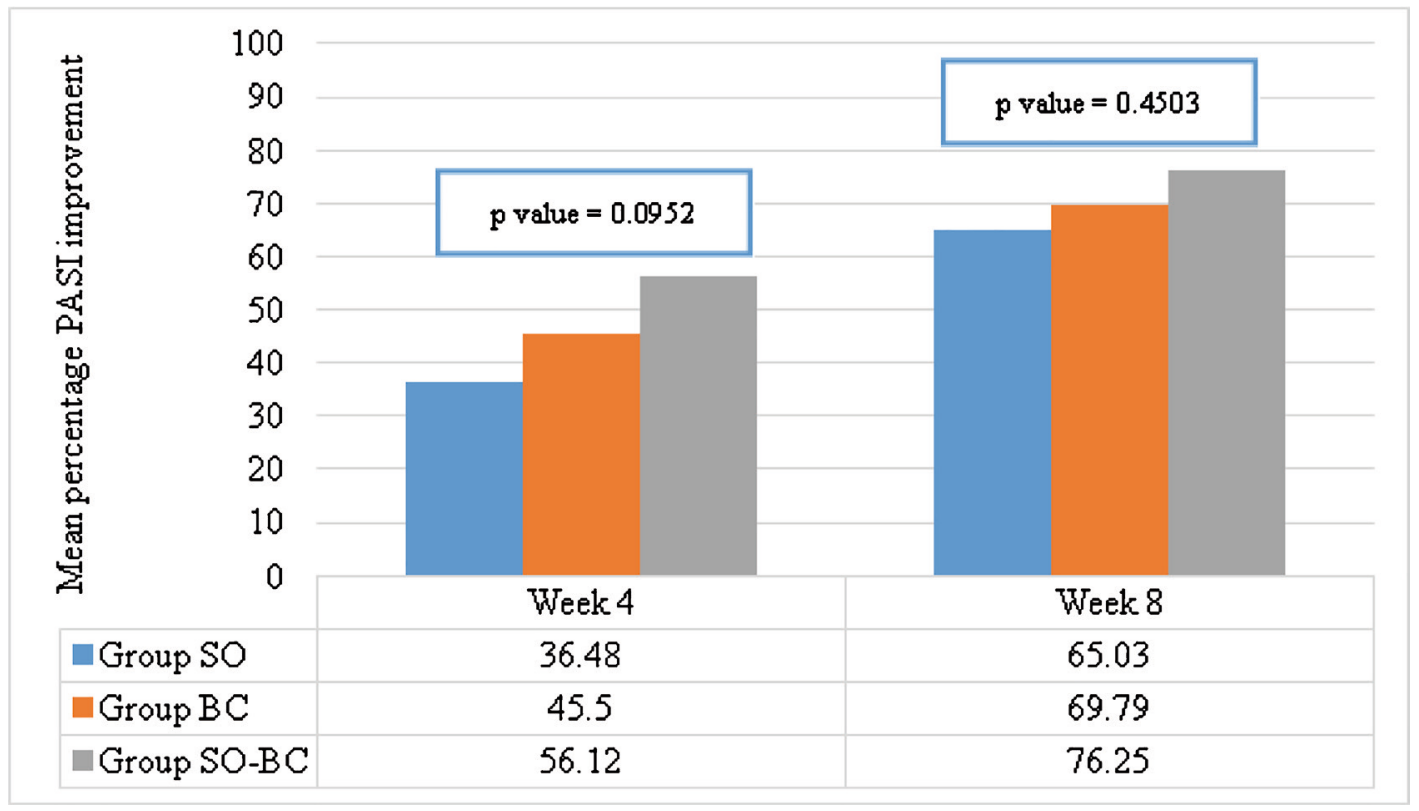

Figure 4. Mean percentage improvement of PASI from baseline at week 4 and week 8 in all treatment arms $(n=51)$

improvement from baseline PASI between treatment groups at both weeks 4 and 8 .

\section{Mean Reduction in Score of the Components of PASI: Erythema, Scaling, Induration}

Table 2 shows the mean reduction in score of erythema, scaling, and induration from baseline and at week 4 and week 8 . Mean reduction in erythema was higher in Group SO-BC $(0.49,0.70)$ followed by Group BC $(0.41,0.67)$ and lastly Group SO $(0.32,0.48)$ at weeks 4 and 8 , respectively. However, the mean reduction in erythema was not statistically significant across the three groups in both week 4 and week 8 .

In terms of scaling, mean reduction in score of scaling significantly differed across the treatment groups. Further analysis revealed that mean reduction in score was significantly higher in Group SO-BC compared to Groups SO and BC both at week 4 and week 8 .

Mean reduction in induration was not statistically significant across the three groups in both week 4 and week 8 . However, there was a higher mean reduction for induration in Group SO-BC followed by Group BC and lastly Group SO in week 4 and week 8.

Table 2. Mean reduction in score of erythema, scaling, and induration from baseline and at week 4 and week 8 in all treatment arms $(n=51)$

\section{Group SO: \\ Sunflower oil + \\ placebo cream \\ Mean \pm SD}

\section{Group BC: \\ Betamethasone \\ valerate cream + placebo oil \\ Mean \pm SD}

\section{Group SO-BC: \\ Sunflower oil + \\ betamethasone \\ valerate cream \\ Mean \pm SD}

\section{Erythema}

Week 4

$0.32 \pm 0.30$

$0.41 \pm 0.43$

$0.49 \pm 0.40$

0.4285

Week 8

$0.48 \pm 0.28$

$0.67 \pm 0.50$

$0.70 \pm 0.41$

0.2827

\section{Scaling}

Week 4

$0.27 \pm 0.21$

$0.25 \pm 0.21$

$0.53 \pm 0.28$

$0.0026^{*}$

Week 8

$0.41 \pm 0.32$

$0.41 \pm 0.27$

$0.79 \pm 0.41$

0.0036 *

\section{Induration}

Week 4 


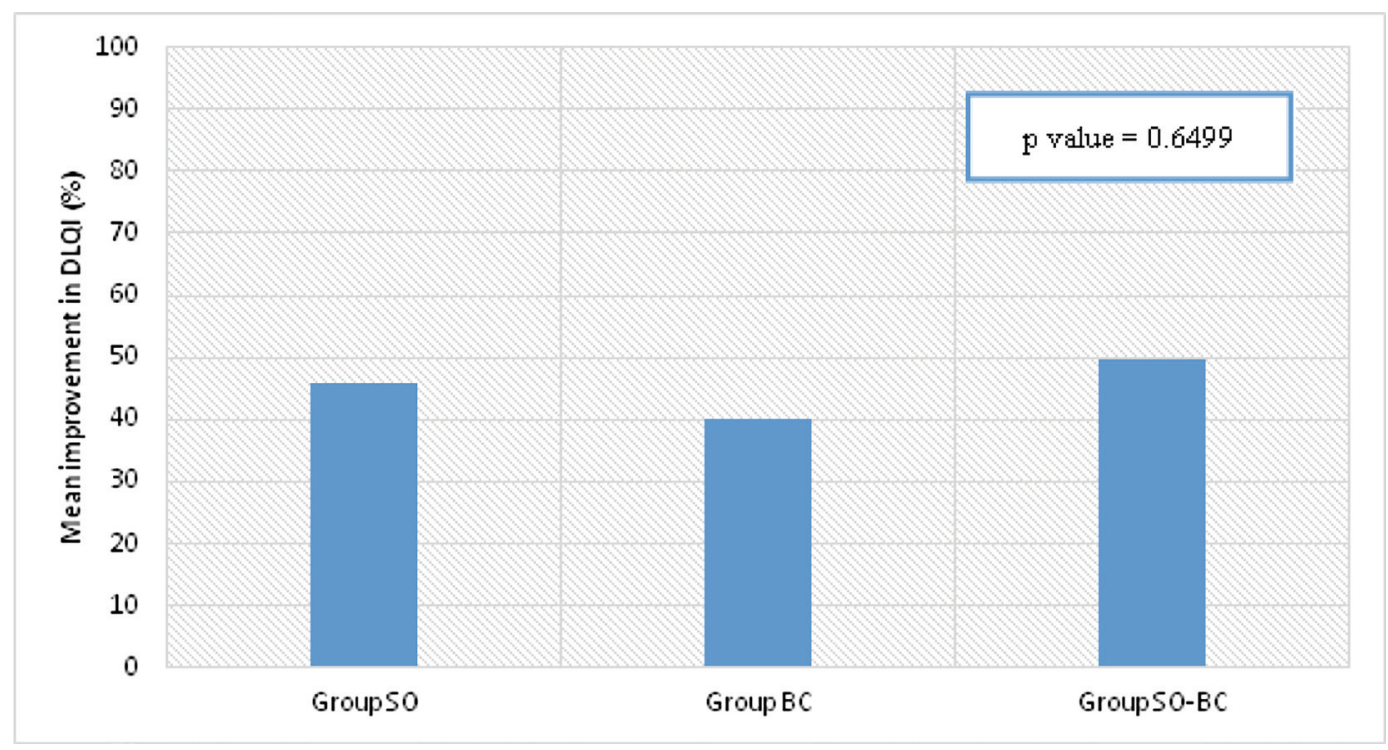

Figure 4. Mean improvement of DLQI at week 8 by treatment arm $(n=51)$

\section{Dermatology Life Quality Index (DLQI)}

Figure 5 shows the improvement in DLQI at week 8 in the three treatment groups. Group SO-BC $(49.73 \%)$ had the highest mean improvement followed by Group SO (45.78\%) and lastly Group BC (40.18\%). However, the mean improvement of DLQl among the three groups was not statistically significant ( $p$-value $=0.6499$ ).

\section{Safety}

Adverse skin reactions were not seen in all study groups for the entire treatment duration.

\section{Sensitivity Analysis}

Figure 5 shows the proportion of patients who achieved PASI $\geq 50$ by treatment group at week 4 and week 8 using per protocol analysis. At week 4, PASI 50 was achieved by $27 \%$ patients in Group SO, $40 \%$ in Group BC, and 60\% in Group SO-BC. There was a further increase in proportion of patients who achieved PASI 50 in week 8. Eighty percent of patients in both Groups SO and BC, and 93\% of patients in Group SO-BC achieved PASI 50 at week 8 . The proportion of patients who achieved PASI 50 did not significantly differ across treatment arms in both week 4 (p-value = 0.216 ) and week 8 (p-value $=0.668)$.

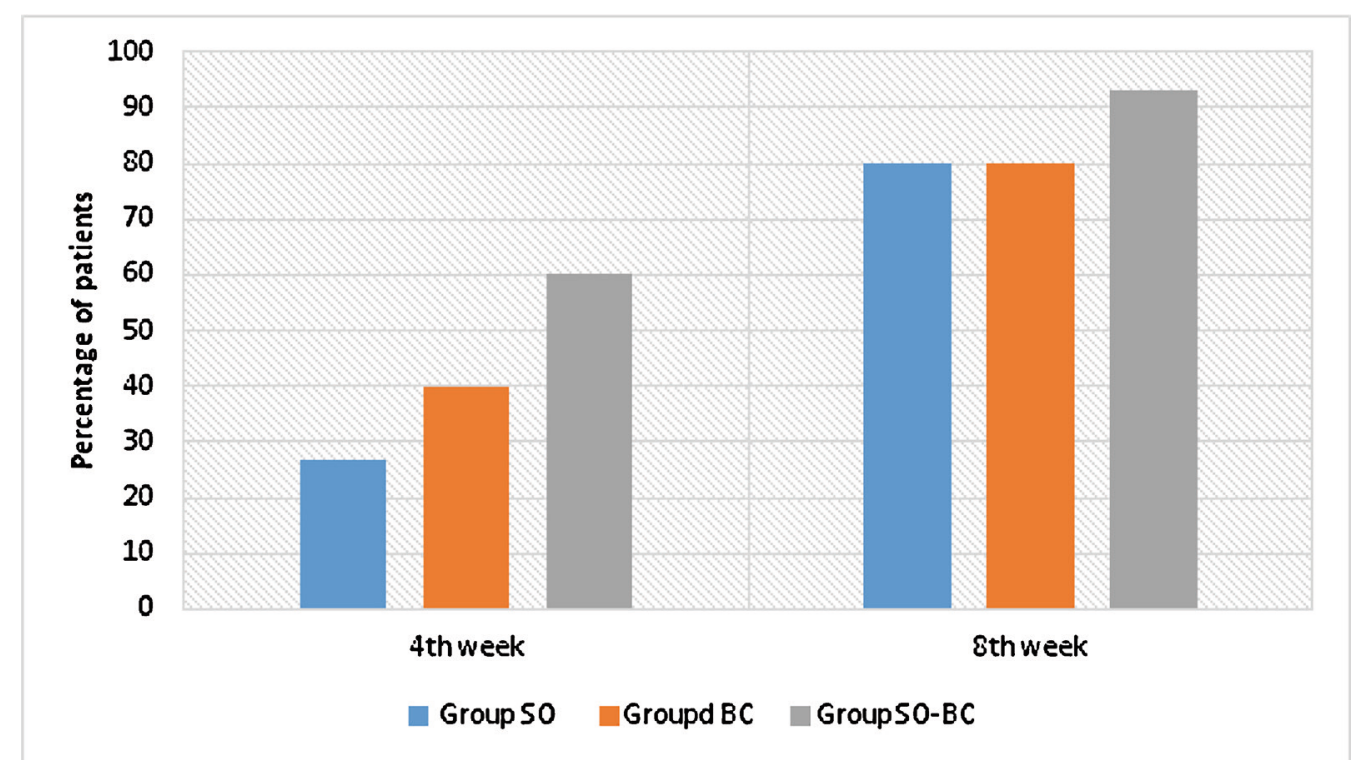

Figure 5. Percentage of patients who achieved PASI 50 at week 4 and week 8 by treatment arm using per protocol analysis ( $\mathrm{n}=45$ ) 


\section{DISCUSSION}

\section{Efficacy of Sunflower Oil}

This study shows that sunflower oil can be used as a monotherapy for psoriasis, achieving equal PASI 50 in $80 \%$ of patients similar to the standard steroid cream. This can be attributed to its anti-inflammatory property. Sunflower oil has a high content of linoleic acid which is a potent activator of peroxisome proliferator activated receptor-alpha (PPAR-alpha). [12] In an experiment made by Rivier et al, they demonstrated that there was a decrease in PPARalpha in the lesional skin of patients with psoriasis. [25] A topical PPAR-alpha agonist was shown to decrease tumor necrosis factor alpha (TNF-alpha) and interleukin-1 alpha in the skin.[26] TNF-alpha plays a central role in the pathogenesis of psoriasis. It is a pro-inflammatory cytokine produced by activated $T$ cells and dendritic cells and it works synergistically with other cytokines to promote inflammation. Thus, a PPAR-alpha agonist like sunflower oil can reduce TNF-alpha leading to the improvement of psoriasis.

Another mechanism of sunflower oil in psoriasis is its moisturizing effect. Psoriasis skin exhibits increased transepidermal water loss (TEWL) along with its associated decreased barrier function, which was found to be correlated to the severity of psoriasis. [27] Moisturizers are considered adjuncts in the treatment of psoriasis. It enhances the penetration of other topical medications by increasing the hydration of the stratum corneum.[28] Studies on sunflower oil showed that it preserved the stratum corneum integrity, improved skin hydration by $18 \%$, and reduced dryness and scaling by $54 \% .[12,29]$ Sunflower oil is composed of $55-70 \%$ linoleic acid, an essential polyunsaturated omega-6 fatty acid with 2 cis double bonds. [30] A linoleic acid transporter is present on keratinocytes that enables the absorption of sunflower oil which contributes to the formation of a functional epidermal barrier.[3 1] This essential fatty acid together with the activation of PPARalpha receptor helps maintain the skin barrier and decrease transepidermal water loss.[29]

The efficacy of sunflower oil was further seen in the decrease of the mean PASI score. This study shows that there was continuous improvement in the sunflower oil group from baseline till the end of treatment.

Furthermore, the mean percentage improvement in PASI at week 8 showed $65 \%$ in Group SO and
$70 \%$ in Group BC. This is similar in literature in which a mid-potent corticosteroid cream achieved a mean percentage improvement in PASI by 60 $69.36 \%$ in 8 weeks.[32,33] The results were also higher compared to moisturizers that were used as controls on different trials which showed improvement of only 15-47\%.[34] Due to its effectiveness as a monotherapy, sunflower oil can be a good treatment option, especially to those patients with steroid phobia. To those who have adverse effects of prolonged steroid use, drug holidays can be recommended by using sunflower oil.

Despite both Groups BC and SO-BC being given a similar steroid cream, Group SO-BC had a higher percentage improvement in PASI from week 4 and was able to sustain it effectively till the end of treatment when compared to Group BC. The mineral oil in Group BC only exhibits moisturizing properties and does not significantly decrease PASI from baseline to 12 weeks of treatment.[35-37] This highlights the advantage of the additive effect of sunflower oil to the standard topical steroids treatment in mild to moderate psoriasis.

In terms of erythema, Groups BC and SO$B C$ had a higher mean reduction in score when compared to Group SO alone. Sunflower oil has no vasoconstrictive effect. Steroid creams however induce vasoconstriction of the blood vessels in the upper dermis which can result in early decrease of lesion erythema.[38] Group SO-BC showed a statistically significant reduction of score in scaling and had the highest decrease in induration compared to the other groups. The inherent properties of sunflower oil is to decrease TNF-alpha and improve skin barrier function along with its moisturizing property that can enhance the absorption of the vasoconstrictive, anti-inflammatory, and anti-mitotic effects of steroids. All these lead to decrease in scores of all the components of PASI.[29,38] The additive effect of both medications may decrease the amount and duration as well as the risks of adverse reactions to topical steroids.

The per protocol analysis showed similar results with the intention to treat analysis and thus similar findings can be concluded.

\section{Improvement in Quality of Life}

There was a $40-50 \%$ improvement in the DLQI scores in the three groups. The mean improvement of 
DLQI scores among the groups was not statistically significant. This shows that whether you use sunflower oil, a standard steroid cream, or a combination of both will all give improvement in the quality of life.

\section{Safety of Sunflower Oil}

Adverse skin reactions were not seen in all study groups for the entire treatment duration.

Studies on sunflower oil recommended its use in all skin types. It does not cause irritation or erythema on the skin of normal individuals, neonates, and patients with atopic dermatitis.[10-12]

\section{Limitations and Generalisability}

Post-hoc power analysis showed only $16 \%$ and $34 \%$ statistical power to detect a significant difference in between groups for the primary outcome of interest in week 4 and week 8 , respectively. The non-significant difference in between groups could have been due to a high beta error or there is really no significant difference between the groups. The study included adult patients with mild to moderate psoriasis, thus the results may be different in pediatric patients.

\section{CONCLUSION}

This study showed that sunflower oil is effective and safe in mild to moderate chronic plaque-type psoriasis. The proportion of patients who achieved
PASI $\geq 50$ at week 8 was similar in Groups SO and BC while Group SO-BC achieved a higher proportion. The mean percentage change of PASI was the highest in Group SO-BC followed by Group BC and Group SO; however, the differences between groups did not reach statistical significance. Baseline PASI was significantly higher and showed a decreasing trend in both week 4 and week 8 in all treatment groups. There was a $40-50 \%$ relative improvement in the DLQI scores in the three groups. There was no incidence of adverse events for each treatment group for the entire treatment duration.

\section{RECOMMENDATION}

The mean PASI score showed a decreasing trend in week 4 and week 8 in Groups SO and SO-BC. This study recommends a longer duration to see the maximum treatment effect of sunflower oil. A research study with a larger population to detect significant difference between groups is also warranted. We also recommend exploring the role of sunflower oil as a steroid-sparing agent. 


\section{REFERENCES}

1. Michalek I, Loring B. Global report on PSORIASIS. World Health Organization. 2016.

2. Raychaudhuri SK, Maverakis E, Raychaudhuri SP. Diagnosis and classification of psoriasis. Autoimmunity Reviews [Internet]. 2014 Apr;13(4-5):490-5. Available from: http:// dx.doi.org/10.1016/i.autrev.2014.01.008

3. Gonzales NG, Guevara BK, Visitaction LR. Patient preference on psoriasis treatment in a Philippine tertiary hospital: A conjoint analysis. J Phil Dermatol Soc. 2017. ISSN: 2094-201X

4. Menter A, Korman NJ, Elmets CA, Feldman SR, Gelfand JM, Gordon KB, et al. Guidelines of care for the management of psoriasis and psoriatic arthritis. Journal of the American Academy of Dermatology [Internet]. 2009 Apr;60(4):64359. Available from: http://dx.doi.org/10.1016/i. jaad.2008.12.032

5. Samarasekera EJ, Sawyer L, Wonderling D, Tucker R, Smith $\mathrm{CH}$. Topical therapies for the treatment of plaque psoriasis: systematic review and network meta-analyses. British Journal of Dermatology. 2013;168:954-67.

6. Li AW, Yin ES, Antaya RJ. Topical corticosteroid phobia in atopic dermatitis. JAMA Dermatol [Internet]. 2017 Oct $1 ; 153(10): 1036$. Available from: http://dx.doi. org/10.1001/jamadermatol.2017.2437

7. Song SY, Jung S-Y, Kim E. Steroid phobia among general users of topical steroids: a cross-sectional nationwide survey. Journal of Dermatological Treatment [Internet]. 2018 Sep 3;30(3):245-50. Available from: http://dx.doi.org/1 $0.1080 / 09546634.2018 .1508817$

8. Press M, Hartop Peter J, Prottey C. Correction of essential fatty-acid deficiency in man by the cutaneous application of sunflower-seed oil. The Lancet [Internet]. 1974 Apr;303(7858):597-9. Available from: http://dx.doi. org/10.1016/s0140-6736(74)92653-1

9. Piccirilli A, Choulot JC, Piccardi N, Msika P. Sunflower oil oleo distillate for atopy treatment: an in vitro and clinical evaluation. Journal of Investigative Dermatology. $2001 ; 117(2): 418$.

10. Pal D. Sunflower (Helianthus annuus L.) Seeds in health and nutrition. In: Nuts and Seeds in Health and Disease Prevention [Internet]. Elsevier; 2011. p. 1097105. Available from: http://dx.doi.org/10.1016/ B978-0-12-375688-6. 10130-6

11. Stoia M, Oancea S. Selected evidence-based health benefits of topically applied sunflower oil. App. Sci. Report. 2015; 10(1):45-9.

12. Danby SG, Alenezi T, Sultan A, Lavender T, Chittock J, Brown K, e al. Effect of olive oil and sunflower seed oil on the adult skin barrier: implications for neonatal skin care. Pediatric Dermatology. 2013;30(1):42-50.

13. Molin L, Cutler TP, Helander I, Nyfors B, Downes N. Comparative efficacy of calcipotriol (MC903) cream and betamethasone 17-valerate cream in the treatment of chronic plaque psoriasis. A randomized, double-blind, parallel group multicentre study. British Journal of Dermatology [Internet]. 1997 Jan; 136(1):89-93. Available from: http:// dx.doi.org/10.1046/j.1365-2133.1997.d01-1148.x

14. Thawornchaisit $P$, Harncharoen K. A comparative study of tar and betamethasone valerate in chronic plaque psoriasis: A study in Thailand. J Med Assoc Thai. 2007;90(10): 1997-2002.
15. Wu J, Feldman S, Lebwohl M. Therapy for Severe Psoriasis. E-book: Expert Consult. 2017:113. Accessed 10 January 2022. Available from: https://books.google.com.tw/boo $\mathrm{ks}$ ?hl=en\&lr=\&id=NlilDQAAQBAJ\&oi=fnd\&pg=PP 1 \&dq= $\mathrm{Wu}+\mathrm{J},+$ Feldman+S,+Lebwohl+M.+Therapy+for+Severe+P soriasis +pdf\&ots $=\mathrm{hjOm} 14 \mathrm{La} 7 \mathrm{~h} \& \mathrm{sig}=\mathrm{ddn} \_\mathrm{p} 8 \mathrm{GPRFN} 1 \mathrm{nnz}$ QkYysWIFysk\&redir_esc $=y \# v=$ onepage \&q $=W u \% 20$ J\%2C\%2OFeldman\%20S\%2C\%20Lebwohl\%20M.\%20 Therapy\%20for\%20Severe\%20Psoriasis\%20pdf\&f=false

16. Bale T, Burden D, Coates L, Hadoke T, MacMahon E, Murphy $R$, et al. Guidelines for biologic therapy for psoriasis. British Association of Dermatologists guidelines. 2017.

17. Informed Health Online. Cologne, Germany: Institute for Quality and Efficiency in Health Care (IQWiG); 2006. Eczema: Steroids and other topical medications. 10 January 2022. Available from: https://www.ncbi.nlm.nih.gov/ books/NBK424899/

18. Cabrera S, Chinniah N, Lock N, Cains GD, Woods J. Inter-observer reliability of the PASI in a clinical setting. Australasian Journal of Dermatology [Internet]. 2015 Mar 5;56(2):100-2. Available from: http://dx.doi. org/10.1111/ajd. 12280

19. Carlin CS, Feldman SR, Krueger JG, Menter A, Krueger GG. A $50 \%$ reduction in the Psoriasis Area and Severity Index (PASI 50) is a clinically significant endpoint in the assessment of psoriasis. J Am Acad Dermatol. 2004;50(6):859-66.

20. Feldman SR. Psoriasis assessment tools in clinical trials. Annals of the Rheumatic Diseases [Internet]. 2005 Mar 1;64(suppl_2):ii65-8. Available from: http://dx.doi. org/10.1136/ard.2004.031237

21. Armstrong AW, Parsi K, Schupp CW, Mease PJ, Duffin KC. Standardizing training for psoriasis measures: effectiveness of an online training video on psoriasis area and severity index assessment by physician and patient raters. JAMA Dermatol. 2013; 149(5):577-82.

22. Berth-Jones J, Grotzinger K, Rainville C, Pham B, Huang J, Daly $S$, et al. A study examining inter- and intrarater reliability of three scales for measuring severity of psoriasis: Psoriasis Area and Severity Index, Physician's Global Assessment and Lattice System Physician's Global Assessment. British Journal of Dermatology [Internet]. 2006 Jun 12;155(4):707-13. Available from: http://dx.doi. org/10.1111/j.1365-2133.2006.07389.x

23. Basra MKA, Fenech R, Gatt RM, Salek MS, Finlay AY. The Dermatology Life Quality Index 1994-2007: a comprehensive review of validation data and clinical results. British Journal of Dermatology [Internet]; 159(5), 997-1035. 2008 Sep; Available from: http://dx.doi. org/10.1111/i.1365-2133.2008.08832.x

24. Kamal T, Haroon T, Hussain liaz. Comparative efficacy of topical calcipotriol with betamethasone valerate in chronic plaque psoriasis. Journal of Pakistan Association of Dermatologists. 2004; 14:16-22.

25. Rivier M, Safonova I, Lebun P, Griffiths CE, Alihaud G, Michel S. Differential expression of peroxisome proliferator-activated receptor subtypes during the differentiation of human keratinocytes. The Society for Investigative Dermatology, Inc. 1998; 111 (6): $1116-21$.

26. Sheu MY, Fowler AJ, Kao J, Schmuth M, Fluhr JW, Man $M Q$, et al. Topical peroxisome proliferator activated receptor-activators reduce inflammation in irritant and allergic contact dermatitis models. The Society for Investigative Dermatology, Inc. 2002;118(1):94-101. 
27. Rim JH, Jo SJ, Park JY, Park BD, Youn Jl. Electrical measurement of moisturizing effect on skin hydration and barrier function in psoriasis patients. Clin Exp Dermatol [Internet]. 2005 Jul;30(4):409-13. Available from: http://dx.doi. org/10.1111/i.1365-2230.2005.01773.x

28. Fluhr JW, Cavallotti C, Berardesca E. Emollients, moisturizers, and keratolytic agents in psoriasis. Clinics in Dermatology [Internet]. 2008 Jul;26(4):380-6. Available from: http://dx.doi.org/10.1016/j.clindermatol.2008.01.015

29. Eichenfield LF, McCollum A, Msika P. The benefits of sunflower oleodistillate (SOD) in pediatric dermatology. Pediatric Dermatology [Internet]. 2009 Nov;26(6):669-75. Available from: http://dx.doi. org/10.1111/i.1525-1470.2009.01042.x

30. Guo S, Ge Y, Na Jom K. A review of phytochemistry, metabolite changes, and medicinal uses of the common sunflower seed and sprouts (Helianthus annuus L.). Chemistry Central Journal [Internet]. 2017 Sep 29;11(1):95. Available from: http://dx.doi.org/10.1186/s13065-017-0328-7

31. Darmstadt GL, Saha SK, Ahmed AS, Ahmed S, Chowdhury A, Law PA, et al. Effect of skin barrier therapy on neonatal mortality rates in preterm infants in Bangladesh: a randomized, controlled, clinical trial. Pediatrics 2008; 121:522-9.

32. Thawornchaisit $P$, Harncharoen K. A comparative study of tar and betamethasone valerate in chronic plaque psoriasis: a study in Thailand. J Med Assoc Thai. 2007;90: 1997-2002.

33. Choonhakarn C, Busaracome P, Sripanidkulchai B, Sarakarn P. A prospective, randomized clinical trial comparing topical aloe vera with $0.1 \%$ triamcinolone acetonide in mild to moderate plaque psoriasis. Journal of the European Academy of Dermatology and Venereology [Internet]. 2010 Feb;24(2):168-72. Available from: http://dx.doi. org/10.1111/i.1468-3083.2009.03377.x

34. Jacobi A, Mayer A, Augustin M. Keratolytics and emollients and their role in the therapy of psoriasis: a systematic review. Dermatol Ther (Heidelb) [Internet]. 2015 Jan 21;5(1):1-18. Available from: http://dx.doi. org/10.1007/s13555-015-0068-3

35. Evangelista MTP, Abad-Casintahan F, Lopez-Villafuerte L. The effect of topical virgin coconut oil on SCORAD index, transepidermal water loss, and skin capacitance in mild to moderate pediatric atopic dermatitis: a randomized, double-blind, clinical trial. Int J Dermatol [Internet]. 2013 Dec 10;53(1):100-8. Available from: http://dx.doi. org/10.1111/ijd.12339

36. Agero AL, Verallo-Rowel VM. A randomized doubleblind controlled trial comparing extra virgin coconut oil with mineral oil as a moisturizer for mild to moderate xerosis. Dermatitis: contact, atopic, occupational, drug. 2004; 15(3): 109-16.

37. Brown AC, Koett J, Johnson DW, Semaskvich NM, Holck $P$, Lally $D$, et al. Effectiveness of kukui nut oil as a topical treatment for psoriasis. Int J Dermatol [Internet]. 2005 Aug;44(8):684-7. Available from: http://dx.doi. org/10.1111/j.1365-4632.2005.02634.x

38. Gabros S, Zito PM. Topical Corticosteroids. In: StatPearls [Internet]. Treasure Island (FL): StatPearls Publishing; 2021 Jan. Accessed 10 January 2022. Available from: https://www.ncbi.nlm.nih.gov/books/ NBK532940/\#_NBK532940_pubdet_

(c) (1)(2) Open Access This article is licensed under a Creative Commons Attribution-NonCommercialShareAlike 4.0 International License, which permits use, share - copy and redistribute the material in any medium or format, adapt - remix, transform, and build upon the material, as long as you give appropriate credit, provide a link to the license, and indicate if changes were made. You may do so in any reasonable manner, but not in any way that suggests the licensor endorses you or your use. You may not use the material for commercial purposes. If you remix, transform, or build upon the material, you must distribute your contributions under the same license as the original. You may not apply legal terms or technological measures that legally restrict others from doing anything the license permits. The images or other third party material in this article are included in the article's Creative Commons license, unless indicated otherwise in a credit line to the material. If material is not included in the article's Creative Commons license and your intended use is not permitted by statutory regulation or exceeds the permitted use, you will need to obtain permission directly from the copyright holder. To view a copy of this license, visit https://creativecommons.org/licenses/by-nc-sa/4.0/. 


\section{APPENDICES}

\section{APPENDIX A. Data Collection Sheet}

STUDY NUMBER:

\section{A. DEMOGRAPHIC AND CLINICAL INFORMATION}

Age

Sex

BMI

Duration of disease

Previous medications:

Underlying disease

Check all that applies years old

o Male o Female

months years

o Topicals:

- Phototherapy

o Systemic treatment:

- Biologics

- Hypertension

- Diabetes mellitus

o Dyslipidemia

Others:

\section{B. DERMATOLOGIC ASSESSMENT}

Baseline

Wk4

Wk8

PASI

DLQI

\section{ADVERSE EVENT}

Week 4

Check all that applies

\section{Week 8}

Check all that applies

\author{
o Erythema ("pamumula") \\ o Stinging sensation/pain ("pagkahapdi") \\ o Pruritus ("pangangati") \\ o Others: \\ o Erythema ("pamumula") \\ o Stinging sensation/pain ("pagkahapdi") \\ o Pruritus ("pangangati") \\ o Others:
}


APPENDIX B: Psoriasis Area and Severity Index (PASI)

Study Number:

Date of visit:

Week:

\begin{tabular}{llllll}
\hline \multicolumn{1}{c}{ Plaque characteristic } & Lesion Score & Head & Upper limbs & Trunk & Lower limbs \\
\hline Erythema & 0 & $=$ None & & \\
& 1 & $=$ Slight & & \\
Induration/thickness & 2 & $=$ Moderate & & \\
3 & $=$ Severe & & \\
Scaling & 4 & $=$ Very severe &
\end{tabular}

Add together each of the 3 scores for each body region to give 4 separate sums (A)

Lesion Score Sum (A)

Multiply by Area Score

Area Score (B)

Degree of involvement as a percentage for each

body region affected (score each region with score

between $0-6$ )

$0=0 \%$

$1=<10$

$2=10-<30 \%$

$3=30-<50 \%$

$4=50-<70 \%$

$5=70-<90 \%$

$6=90-<100 \%$

Subtotals (C) Multiply Lesion Score Sum (A) by Area Score (B), for each body region, to give four individual subtotals (C)

Multiply each of the Subtotals (C) by amount of body $\quad \times 0.1 \quad \times 0.2 \quad \times 0.3 \quad \times 0.4$ surface area represented by that region.

Total (D)

PASI: $(A+B+C+D)$ 


\section{APPENDIX C: DERMATOLOGY LIFE QUALITY INDEX (DLQI)}

Study Number: Date of visit:

Week:

The aim of this questionnaire is to measure how much your skin problem has affected your life OVER THE LAST WEEK. Please tick one box for each question.

1. Over the last week, how itchy, sore, painful or stinging has your skin been?

2. Over the last week, how embarrassed or self-conscious have you been because of your skin?

Very much

A lot

A little

Not at all

Very much

A lot

A little

Not at all

3. Over the last week, how much has your skin interfered with you going shopping or looking after your home or garden?

Very much

A lot

A little

Not at all

Not relevant

4. Over the last week, how much has your skin influenced the clothes you wear?

Very much

A lot

A little

Not at all

Not relevant

5. Over the last week, how much has your skin affected any social or leisure activities?

Very much

A lot

A little

Not at all

Not relevant

6. Over the last week, how much has your skin made it difficult for you to do any sport?

Very much

A lot

A little

Not at all

Not relevant

7. Over the last week, has your skin prevented you from working or studying?

If "No", over the last week how much has your skin been a problem at work or studying?

8. Over the last week, how much has your skin created problems with your partner or any of your close friends or relatives?

Yes

No

Not relevant

A lot

A little

Not at all

Very much

A lot

A little

Not at all

Not relevant

9. Over the last week, how much has your skin caused any sexual difficulties?

Very much

A lot

A little

Not at all

Not relevant

10. Over the last week, how much of a problem has the treatment for your skin been, for example by making your home messy, or by

Very much

A lot

A little

Not at all

Not relevant 
SCORING

\section{Very much}

A lot

A little

Not at all

Not relevant

Question 7, "prevented work or studying"

\author{
Scored 3 \\ Scored 2 \\ Scored 1 \\ Scored 0 \\ Scored 0 \\ Scored 3
}

The DLQI is calculated by adding the score of each question resulting in a maximum of 30 and a minimum of 0 . The higher the score, the more quality of life is impaired.

\begin{tabular}{|ll}
\hline 0-1 & no effect at all on patient's life \\
$2-5$ & small effect on patient's life \\
6-10 & moderate effect on patient's life \\
$11-20$ & Very large effect on patient's life \\
$21-30$ & Extremely large effect on patient's life \\
\hline
\end{tabular}

(c) A Y Finlay, G K Khan, April 1992. www.dermatology.org.uk. The above permission does not affect the requirement for seeking of permission and of possible payment when the DLQI is used for research or other purposes. 


\section{APPENDIX D. Taluntunin ng kalidad ng buhay na hinggil sa dermatolohiya (DLQI)}

Study Number: Araw ng Pagbisita: Linggo:

Ang layunin ng palatanungang ito ay upang masukat kung gaano naapektuhan $\mathrm{ng}$ iyong problema sa balat ang iyong buhay SA NAKARAANG LINGGO. Mangyaring lagyan ng tsek ang isang kahon para sa bawat tanong.

1. Sa nakaraang linggo, gaano kakati, kakirot, kasakit o kahapdi ang iyong balat?

2. Sa nakaraang linggo, gaano ka napahiya o may labis na kamalayan sa tingin ng ibang tao dahil sa iyong balat?

3. Sa nakaraang linggo, gaano nakasagabal ang iyong balat sa iyong pamimili o pag-aasikaso sa iyong bahay o bakuran?

4. Sa nakaraang linggo, gaano nakaimpluwensya ang iyong balat sa mga damit na iyong sinusuot?

5. Sa nakaraang linggo, gaano nakaapekto ang iyong balat sa anumang mga gawaing pakikisalamuha sa tao o panlibangan?

6. Sa nakaraang linggo, gaano nagpahirap ang iyong balat na makalaro ka sa anumang isport?

7. Sa nakaraang linggo, nahadlangan ka ba ng iyong balat na makapagtrabaho o makapag-aral?

Kung "Hindi", sa nakaraang linggo, gaano naging problema ang iyong balat sa trabaho o pag-aaral?

8. Sa nakaraang linggo, gaano nakalikha ng mga problema ang iyong balat sa iyong kapareha o sa sinuman sa iyong mga malalapit na kaibigan $\circ$ kamag-anak?

9. Sa nakaraang linggo, gaano naging sanhi ang iyong balat sa anumang mga kahirapan sa pakikipagtalik?

10. Sa nakaraang linggo, gaano naging problema ang paggamot sa iyong balat, halimbawa, gawing makalat ang iyong tahanan o sa pag-aksaya ng oras?

Labis-labis

Labis

Bahagya

Walang wala

Labis-labis

Labis

Bahagya

Walang wala

Labis-labis

Labis

Bahagya

Walang wala

Hindi angkop

Labis-labis

Labis

Bahagya

Walang wala

Hindi angkop

Labis-labis

Labis

Bahagya

Walang wala

Hindi angkop

Labis-labis

Labis

Bahagya

Walang wala

Hindi angkop

Oo

Hindi

Labis

Bahagya

Walang wala

Labis-labis

Labis

Bahagya

Walang wala

Hindi angkop

Labis-labis

Labis

Bahagya

Walang wala

Hindi angkop

Labis-labis

Labis

Bahagya

Walang wala

Hindi angkop 
PAGMAMARKA

\begin{tabular}{|ll}
\hline Labis-labis & Scored 3 \\
Labis & Scored 2 \\
Bahagya & Scored 1 \\
Walang wala & Scored O \\
Hindi angkop & Scored 0 \\
lka-7 na tanong, nahadlangan ka ba ng iyong balat na & Scored 3
\end{tabular}

makapagtrabaho o makapag-aral?

The DLQI is calculated by summing the score of each question resulting in a maximum of 30 and a minimum of 0 . The higher the score, the more quality of life is impaired.

\begin{tabular}{|ll|}
\hline 0-1 & no effect at all on patient's life \\
2-5 & small effect on patient's life \\
6-10 & moderate effect on patient's life \\
1 1-20 & Very large effect on patient's life \\
21-30 & Extremely large effect on patient's life \\
\hline
\end{tabular}

(c) A Y Finlay, G K Khan. April 1992. www.dermatology.org.uk. The above permission does not affect the requirement for seeking of permission and of possible payment when the DLQI is used for research or other purposes. 


\section{APPENDIX E. - CHI-SQUARE TEST POWER \\ ANALYSIS (sample size)}

Chi-Square Test Power Analysis

Page/Date/Time 1 1/15/2019 8:51:58 AM

\section{Numeric Results for Chi-Square Test}

\begin{tabular}{c|c|c|c|c|c|c} 
Power & $\mathbf{N}$ & $\mathbf{W}$ & Chi-Square & DF & Alpha & Beta \\
\hline 0.90624 & 46 & 0.5300 & 12.9214 & 2 & 0.05000 & 0.09376
\end{tabular}

\section{REFERENCES}

Cohen, Jacob. 1988. Statistical Power Analysis for the Behavioral Sciences, Lawrence Erlbaum Associates, Hillsdale, New Jersey.

\section{Report Definitions}

Power is the probability of rejecting a false null hypothesis. It should be close to one.

$\mathrm{N}$ is the size of the sample drawn from the population. To conserve resources, it should be small.

$W$ is the effect size - a measure of the magnitude of the Chisquare that is to be detected.

DF is the degree of freedom of the Chi-square distribution. Alpha is the probability of rejecting a true null hypothesis. Beta is the probability of accepting a false null hypothesis.

\section{Summary Statements}

A sample size of 46 achieves $91 \%$ power to detect an effect size (W) of 0.5300 using 2 degrees of freedom Chi-square test with a significance level (alpha) of 0.05000 . 